\title{
Torre de Hanói virtual e a construção do conceito de Função Exponencial no Ensino Médio
}

\author{
Adriana Breda - PPGEDUCEM/PUCRS - adriana.breda@gmail.com \\ Viviane Beatriz Hummes - PPGEMAT/UFRGS - vivihummes@gmail.com \\ Valderez Marina do Rosário Lima - PPGEDUCEM/PUCRS - valderez.lima@pucrs.br
}

Resumo: Este trabalho tem como objetivo apresentar uma reflexão sobre o processo de aprendizagem do conceito de Função Exponencial no Ensino Médio, a partir da utilização do jogo Torre de Hanói virtual, através do uso de laptops educacionais. Os dados foram coletados por meio de um questionário inicial, para identificação das ideias prévias dos estudantes e por meio de registros em um diário de campo. Em seguida, os dados foram analisados conforme a metodologia Análise Textual Discursiva, de Moraes \& Galiazzi (2007). A partir da análise, emergiram duas unidades de significado: a primeira indica que a ideia inicial apresentada pelos alunos em relação à Função Exponencial está associada a uma caracterização da linguagem ligada à Função Quadrática, ao passo que a segunda aponta uma transformação da linguagem natural do entendimento da Função Exponencial para a linguagem formal, isto é, a formalização escolarizada do conceito de Função Exponencial.

Palavras-chave: função exponencial, jogo, linguagem, conceitos.

\section{Virtual Hanoi Tower and the construction of concept of Exponential Function in High School}

\begin{abstract}
This paper aims to present a reflection about the learning process of Exponential Function in High School, from the employment of the virtual game Tower of Hanoi through the use of educational laptops. The data were collected by an initial questionnaire, in order to identify the preliminary ideas and to register in a field journal. After the data were analyzed according to the Discursive Textual Analysis. From this analysis two categories emerged: the first indicates that the initial idea which the students presented in relation to the Exponential Function is associated to a characterization of the language to the Quadratic Function. The second category points a transformation of the natural language understanding of Exponential Function to the formal language, that is to say, the formal school concept of Exponential Function.
\end{abstract}

Keywords: exponential function, game, language, concepts

\section{O limiar da pesquisa: a questão inicial como regra do jogo}

Devido às transformações da sociedade, principalmente com os avanços tecnológicos, muitos trabalhos realizados nas escolas, em especial, nas aulas de matemática, têm como preocupação a melhoria dos processos de ensino e aprendizagem, de forma que estes aconteçam de maneira adequada à realidade do alunado do século XXI. Nesse sentido, procuram-se estratégias didáticas que atentem à utilização das tecnologias da informação e comunicação nas aulas de matemática para trabalhar diferentes conteúdos e construir, juntamente com os alunos, os diferentes conceitos matemáticos contemplados na Educação Matemática básica. Um conteúdo bastante problematizado nas pesquisas em Educação Matemática é o estudo da Função Exponencial, seja porque é de difícil compreensão por parte dos alunos, seja porque é um conteúdo que antecede o estudo dos logaritmos, ou, até mesmo, porque é um tópico 
que apresenta diversas aplicações tanto nas áreas das outras ciências exatas, como nas ciências da saúde e nas ciências sociais.

Desta maneira, algumas pesquisas vêm sendo feitas relacionando o estudo da Função Exponencial e o uso da tecnologia, seja para discutir a constituição do conceito de função ou para dispor sobre a função em sua forma gráfica. Um exemplo é o trabalho de Silva (2012) que, a partir de um estudo que possibilitou a identificação das dificuldades dos alunos na compreensão do estudo de Funções Exponenciais e de Funções Logarítmicas, criou uma sequência de atividades que envolvia a resolução de problemas do aspecto cotidiano dos alunos. Este trabalho foi realizado sob o enfoque de Vergnaud (1996) e Duval (2003), e propiciou aos alunos a identificação das variáveis dependentes e independentes e das questões de crescimento e decrescimento em gráficos, a partir da utilização do software Winplot. Assim, os alunos construíram o conceito de Função Exponencial e Logarítmica. Outro exemplo é a dissertação de Berleze (2007) que, a partir do uso da Engenharia Didática e, também, utilizando o software Winplot, elaborou uma sequência de ensino de diferentes tipos de funções, inclusive a Exponencial. A partir da análise das transformações gráficas e da interatividade que os alunos estabeleciam com o programa e com os colegas, foi possível verificar que os estudantes se tornaram autônomos, críticos e criativos. Já, o trabalho de Barroso (2009), aponta para o uso do software Geogebra e o uso do objeto de aprendizagem (OA) Torre de Hanói para promover a construção do conceito de Função Exponencial no terceiro ano do Ensino Médio, onde os alunos preencheram uma tabela relacionando o número de discos e número de jogadas. Os estudos apontam que a utilização das tecnologias serviram para a motivação, iniciativa e colaboração entre os estudantes.

A partir dos estudos apresentados e da problemática envolvida nessa investigação, este trabalho pretende responder a questão: de que maneira é constituído o conceito de Função Exponencial no Ensino Médio a partir do uso do jogo Torre de Hanói virtual? Nesse sentido, a presente pesquisa demonstra que, a partir dos conhecimentos prévios dos alunos, seguidos de uma interação com o jogo denominado Torre de Hanói, pode-se estabelecer uma introdução ao conceito de Função Exponencial no Ensino Médio. Além disso, os próprios alunos chegaram à transformação desse conceito, inicialmente apresentado com a característica de uma linguagem natural, para uma linguagem formal, revelando, um conhecimento formal adquirido durante $\mathrm{o}$ processo de trabalho, corroborando assim, com a idéia de Bicudo \& Garnica (2006), a qual aponta que ato de formalizar consiste na elaboração a partir de um discurso natural centrado na intuição da presença do objeto, este, neste caso, o jogo Torre de Hanói virtual. Abaixo, uma ilustração do layout do objeto de aprendizagem.

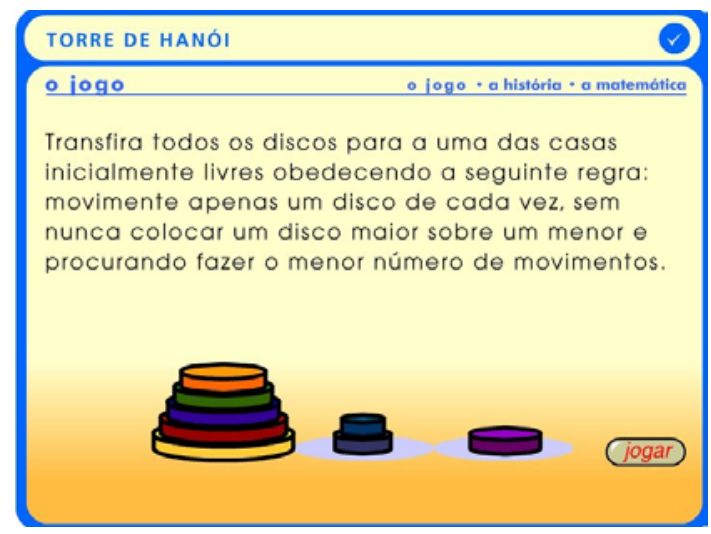

Figura 1. Layout da objeto de aprendizagem Torre de Hanói 
No tópico a seguir, apresentamos o referencial teórico que utilizamos para contextualização da pesquisa. Já, no tópico 3 apresentamos os aspectos metodológicos que utilizamos para a realização da mesma. Os tópicos 4 e 5 apresentam as unidades de significado que emergiram no momento da análise dos dados. No tópico 6 finalizamos a nossa discussão apresentando novos caminhos que podem ser trilhados a partir deste estudo.

\section{Sustentando a ideia: o que já se tem dito sobre jogos, tecnologia e formação conceitual}

A intenção de utilizarmos a tecnologia associada ao estudo de funções está diretamente relacionada com a ideia de que, segundo Portanova et. al. (2005), as tecnologias em sala de aula são utilizadas para a construção do conhecimento e, conforme a intervenção do professor, podem apresentar soluções para determinados problemas, de forma que se efetive uma transformação da realidade.

Utilizamos como instrumento de aprendizagem a Torre de Hanói, pois esta é considerada um jogo didático, devido ao fato de apresentar regras e servir para fins educacionais. Segundo Dante (2002), o jogo é um ótimo instrumento didático, pois durante a realização do mesmo, o aluno é desafiado a pensar, estabelecer estratégias, desenvolvendo, dessa maneira, sua autonomia. Para D’Ambrosio (1994), o jogo nas aulas de matemática é uma ótima estratégia para a produção do conhecimento, pois apresenta uma característica da ação comum, esta, gera a capacidade de explicar, conviver e lidar com a realidade, na qual será acumulada e transmitida para com os pares. Paulo Freire (2006) aponta que o ensinar em um ambiente educacional implica em respeitar os saberes dos educandos, além disso, exige criticidade e autonomia por parte dos mesmos. Nesta perspectiva, acreditamos que trabalhar o jogo associado à tecnologia beneficia o aluno, pois além de possibilitarmos a reconstrução de conceitos matemáticos, podemos promover uma sala de aula criativa, harmoniosa e solidária.

Trabalhar a constituição de um novo conceito através de um ambiente desafiador é não restringi-lo à sua definição, mas sim, assumi-lo como um elemento em que é atribuído sentido e significado pela criança ou adolescente, ou seja, um conceito é algo constituído através da possibilidade de resolução de situações-problema, (Vergnaud, 1996).

Já para Vygotsky (1987), os conceitos propriamente ditos são construídos pela capacidade que a criança e o adolescente têm de abstração e generalização "O conceito surge quando uma série de atributos abstraídos torna a sintetizar-se, e quando a síntese abstrata assim obtida se torna forma basilar de pensamento com o qual a criança percebe e toma conhecimento da realidade que a cerca.” (Vygotsky, 1987, p.226). Nesse sentido, a partir de situações vivenciadas pelos alunos, são construídos por eles modelos e teorias sobre determinado assunto. Cabe ao professor estabelecer estratégias para transformar tais concepções em outras mais rebuscas e formais, (Sztajn, 1997).

\section{Estratégias do jogo: os caminhos percorridos na investigação}

Para a realização deste trabalho, fizemos um estudo de caso (Ponte, 1994; Yin, 2001), que se caracteriza pela análise, em profundidade, de uma situação específica e particular. O estudo foi realizado com uma turma de segundo ano do Ensino Médio composta por trinta alunos e pertencente a uma escola da rede pública de Porto Alegre (RS/Brasil). Constituíram o grupo 14 alunos do sexo masculino e 16 do sexo feminino, com idade variando entre 15 e 17 anos. 
A situação de ensino proposta iniciou com os estudantes preenchendo um questionário, que tinha a intenção de revelar as ideias prévias dos alunos em relação ao que seria e como se delineava uma função do tipo Exponencial. Constituíram esse instrumento de coleta de dados as seguintes perguntas: O que você entende por função? O que você entende por Função Exponencial? Faça um esboço de um gráfico que representa uma Função Exponencial. Na sequência, apresentamos aos alunos o jogo Torre de Hanói virtual, que pode ser jogado com um mínimo de três discos e um máximo de oito, de tal forma que quanto maior o número de discos, maior o número de movimentos mínimos realizados para vencer o jogo. Em seguida, os alunos realizaram uma atividade guiada, que consistia em jogar e registrar o número de movimentos executados quando escolhido determinado número de discos. Ao final da atividade, solicitamos aos alunos que escrevessem quantos movimentos seriam necessários realizar ao se manipular um disco, dois discos, dez discos ou $n$ discos. Além disso, sugerimos aos estudantes que esboçassem o gráfico que representaria tal situação. Após a realização da atividade, os resultados foram socializados a partir da discussão em sala de aula com o grande grupo.

As ações desenvolvidas na situação de ensino foram acompanhadas de forma sistemática e registradas em um diário de campo (Bogdan \& Biklen, 1994). Assim, foi possível estabelecer, no processo de análise, uma relação comparativa entre as respostas dos alunos ao questionário inicial, as reflexões/discussões expressas durante a atividade e os resultados emergentes no momento pós-atividade.

A análise dos dados foi realizada a partir da Análise Textual Discursiva - ATD, proposta por Moraes e Galiazzi (2007). Esse tipo de análise tem por procedimentos a unitarização, a construção de unidades de significado e a construção do metatexto, isto é, um texto no qual estão implicadas as ideias do material coletado, a percepção do pesquisador e os fundamentos teóricos utilizados na pesquisa, com fins interpretativos.

\section{A Função Exponencial como uma Função Quadrática: uma questão de linguagem}

Ao iniciarmos a apresentação dos resultados, entendemos que algumas respostas proferidas pelos alunos a partir do questionário inicial, que consistia em saber o que os alunos entendiam por Função Exponencial e qual seria sua forma gráfica, merecem uma atenção especial. Dentre as respostas apresentadas, destacamos que para o aluno R, por exemplo, uma função exponencial "É algo que está elevado em alguma potência” (aluno R). Este mesmo aluno representou o esboço do gráfico de uma função exponencial como se fosse uma parábola com concavidade voltada para baixo. Ao mesmo tempo, o aluno L proferiu: "Pra mim função é a conta que soluciona a reta, curvatura e etc." "Eu entendo que função exponencial é quando a fórmula do gráfico tem o expoente $\left(\mathrm{x}^{2}\right)$ sobre um número. Ex: $\mathrm{a}^{2}+\mathrm{b}-\mathrm{c}$ ”, (aluno $\mathrm{L}$ ). Abaixo seguem a Figura 2 e a Figura 3, as quais expressam a representação gráfica feita pelo aluno $\mathrm{R}$ e pelo aluno L, respectivamente, de como seria o comportamento gráfico de uma função do tipo Exponencial. 


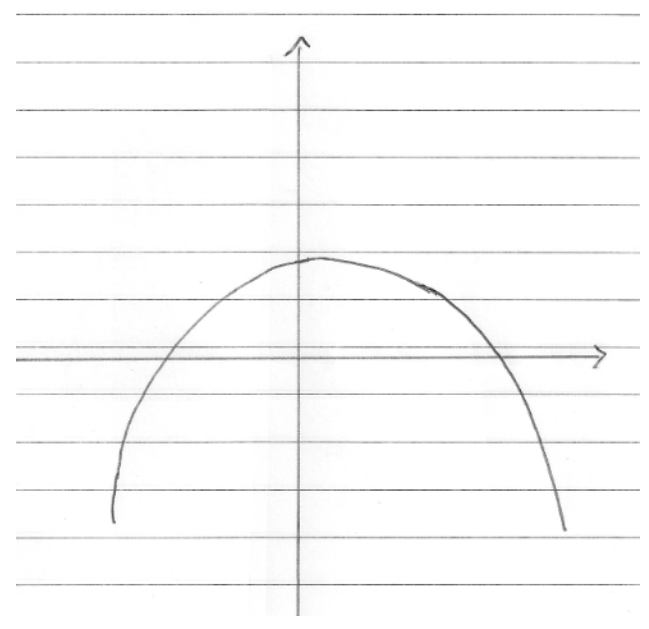

Figura 2. Representação do aluno R

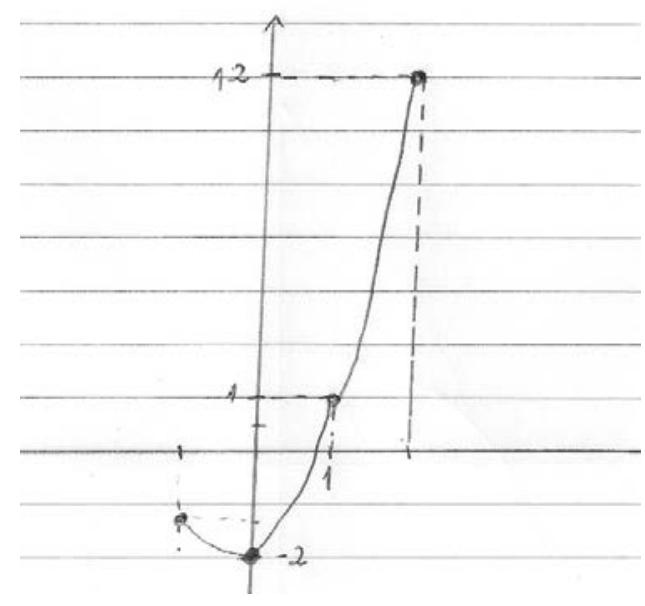

Figura 3. Representação do aluno L

Os alunos expressaram a Função Exponencial, seja em palavras ou em representação gráfica, como se fosse uma Função Quadrática, pois em suas concepções "ao quadrado" é expoente, ou seja, associam o nome exponencial a expoente. Para Vygotsky (1987), esta é uma questão que está diretamente relacionada à linguagem. É através da linguagem que são expressados e internalizados os significados constituídos através da vivência e das interações sociais que a criança ou o adolescente estabelece durante sua trajetória. As preferências, concordâncias e os antagonismos são expressões dos significados sociais que eles estabelecem.

Nesse sentido, compreendemos que o entendimento que os alunos trouxeram do que seria uma Função Exponencial, em um primeiro momento, remete à ideia de Função Quadrática, seja na forma verbal, gráfica, ou até mesmo na tentativa de formalização genérica, constituída pelo aluno L, por exemplo. Essas associações nada mais são que questões relacionadas à linguagem. Em algum outro momento, em algum outro espaço de socialização escolar os alunos internalizaram ou associaram a ideia de expoente à $x^{2}$ e quando escutaram a palavra exponencial, já se remeteram à ideia de expoente, isto é, de $x^{2}$.

García (1998) apóia-se em Pozo (1994), para apontar que o conhecimento que entendemos por intuitivo, muito dificilmente é abandonado, pois apresenta raízes fortes em função de ser constituído, muitas vezes, historicamente e socialmente. A partir do exposto, se torna interessante a intervenção do professor enquanto mediador e promotor da aprendizagem, pois desconstruir o que já está previamente construído/internalizado pelos alunos não é tarefa simples e talvez nem seja necessário. O importante é encontrar estratégias que motivem e promovam a capacidade do aluno de resolver problemas e enfrentar desafios, de forma que este possa atribuir significado ao que está realizando.

Dessa forma, a partir do jogo Torre de Hanói virtual, os alunos puderam realizar uma transformação dos seus conhecimentos prévios sobre Função Exponencial, o que, segundo Moreira (2006), vai ao encontro do "[...] processo de interação pelo qual conceitos mais relevantes e inclusivos interagem com o novo material servindo de ancoradouro, incorporando-o e assimilando-o, porém, ao mesmo tempo, modificando-se em função dessa ancoragem” (Moreira, 2006, p. 15). Nesse sentido, os alunos puderam ir além da manipulação dos discos ofertados pelo jogo, que eram de no mínimo três e no máximo oito, e assim, puderam estabelecer relações para um maior número de discos. É o que apresentaremos no capítulo a seguir. 


\section{Da linguagem natural à linguagem formal: o entendimento do conceito de Função Exponencial e a formalização da situação estudada}

Durante a aplicação do jogo e da realização do estudo dirigido, os alunos conseguiram construir uma tabela relacionando o número de discos com o número mínimo de jogadas necessárias para vencer o jogo. Nesse processo, os alunos foram questionados sobre qual é a relação que poderia ser estabelecida entre o número de discos e o número mínimo de jogadas quando se tem nove discos, dez discos e n discos. Um dos alunos comentou "Se para três discos são sete e para quatro discos são quinze, então só pode ser sempre o dobro acrescentado de um” (aluno R). Assim, os alunos demonstraram estar desafiados a encontrar uma relação genérica que valesse para qualquer número de discos.

Conforme Martins (1999), a partir do momento em que o educando está em contato com jogo Torre de Hanói virtual, dentro de um espaço escolar, espera-se que o conceito, anteriormente considerado espontâneo, adquira um grau de abstração que tem como objetivo, segundo Vygotsky, definir o conceito científico. "A aprendizagem dos conceitos científicos adquiridos [...] se dá na e pela interação com professores e colegas, apóia-se em um conjunto previamente desenvolvido de conhecimentos originários das experiências diárias da criança. Esse conhecimento, espontaneamente adquirido, passa a ser o mediador da aprendizagem de novos saberes.” (Martins, 1999, p.119).

Sob essa perspectiva, no momento de socialização dos resultados em sala de aula, outras relações foram sendo estabelecidas pelos alunos. Alguns exclamaram que era necessário fazer o triplo do número de discos e subtrair duas unidades, outros simplesmente apontaram que não havia uma solução para o problema, até que o aluno L disse "[...] é só fazer o dois elevado no número de discos e diminuir um" (aluno L), em outras palavras, $f(n)=2^{n}-1$. Foi no momento da troca de ideias que os alunos conseguiram transformar uma relação que se apresentava em uma linguagem natural em outra linguagem, na qual denominamos de formal.

Para Gomez-Granell (1998), a linguagem natural, aquela expressada pela fala e escrita, desempenha uma função primordial no estabelecimento de novos símbolos matemáticos e, assim, dificulta a perda do sentido construído através do processo de abstração. Por outro lado, é interessante que esse significado seja devolvido às formas simbólicas da matemática, pois dessa maneira, possibilita que ela entre nas ciências do mundo exterior, como por exemplo, a biologia, a sociologia, etc. Para García (1998), o conhecimento escolar é um conhecimento construído na escola que conversa com outras formas de conhecimentos, sejam eles científicos, cotidianos, filosóficos, etc.

A partir dessa esteira, verificamos que o conhecimento adquirido pelo aluno, ao esquematizar as relações através do jogo Torre de Hanói virtual, foi considerado um conhecimento particular adaptado às características do contexto escolar, pois a atividade foi além daquilo que pôde ser observado e manipulado. Além disso, contemplou aquilo que deveria ser abstraído, isto é, a partir das relações estabelecidas entre o número de discos e o número de jogadas observáveis, possibilitou aos alunos inferir a mesma relação para as jogadas não observáveis, como se tivéssemos nove discos, dez discos, ou $n$ discos. A figura abaixo ilustra o comportamento gráfico e a relação genérica estabelecida entre número de discos e número mínimo de jogadas produzido pelo aluno $\mathrm{R}$. 


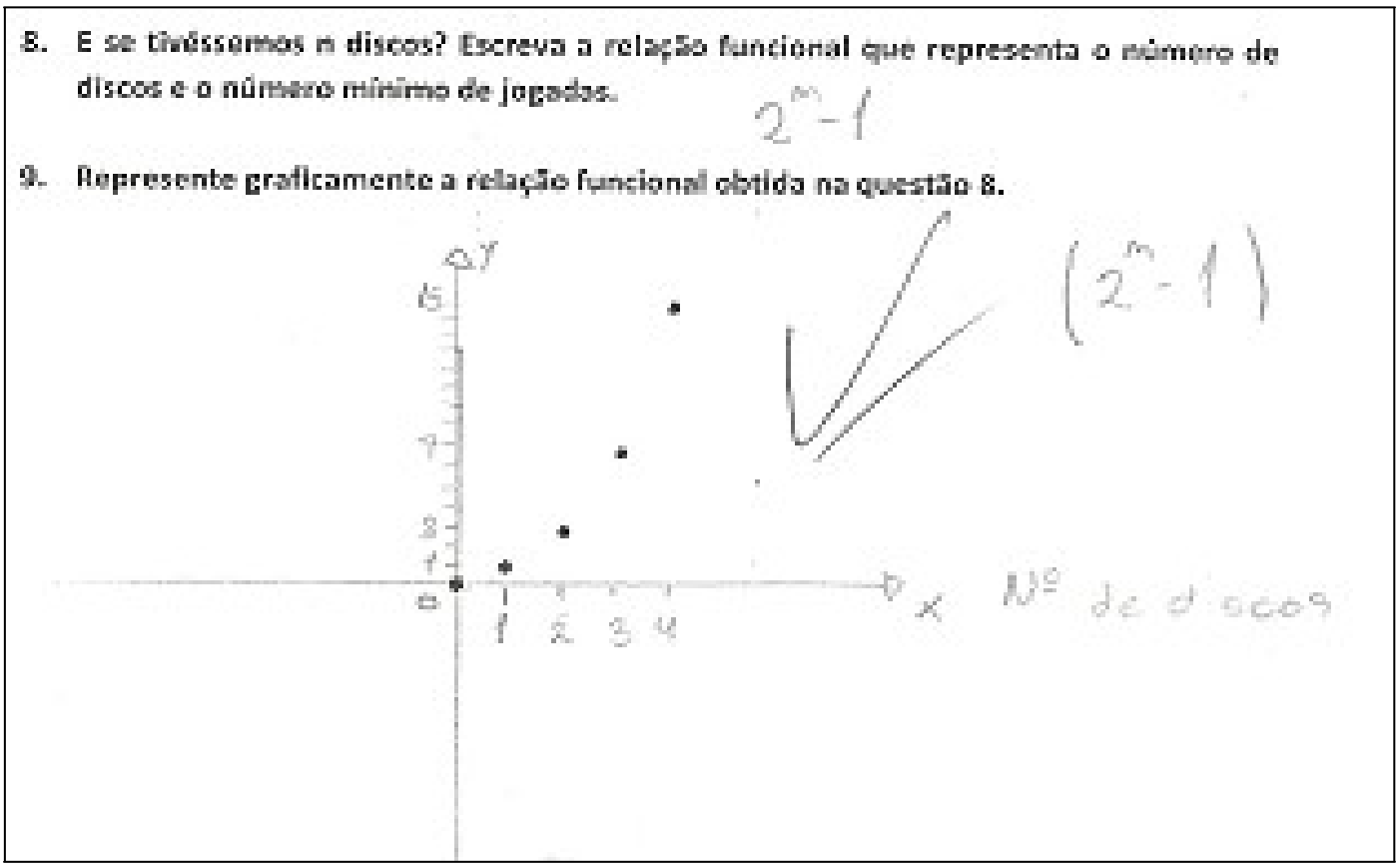

Figura 4. Representação gráfica produzida pelo aluno R

Diante desse contexto, compreendemos que a totalidade da atividade proposta levou, a partir do intuitivo, a uma formação conceitual, melhor dizendo, uma formação e formalização conceitual escolar de cunho muito particular e vamos explicar o porquê. Em primeiro lugar, a formalização e a conceituação se deu a partir de um caso particular, isto é, de um comportamento exponencial. Em segundo lugar, porque a Função Exponencial é definida no conjunto dos números reais e neste caso, abordamos somente o universo do conjunto dos números naturais. Dessa forma, é importante deixar claro para os alunos que Função Exponencial não se restringe à matemática da Torre de Hanói, mas nela, pode-se começar os primeiros passos do pensar exponencialmente.

\section{Finalizando o jogo: algumas considerações}

Toda trajetória percorrida até aqui, nos fez refletir sobre alguns aspectos. Um deles é que compreendemos que os "supostos" erros apresentados inicialmente pelos alunos, isto é, caracterizar uma Função Exponencial como uma Função Quadrática, podem estar vinculados a uma questão de linguagem. Outro aspecto importante foi o sucesso dos alunos quando estes conseguiram estabelecer uma conceituação significativa de Função Exponencial a partir do uso do jogo Torre de Hanói virtual. Pois, ao se sentirem autônomos, os alunos foram capazes de construir seu próprio conhecimento, formalizando que, para a situação trabalhada, obtemos uma função do tipo $f(n)=2^{n}-1, n$.

Outros caminhos podem ser percorridos ao trabalhar a Função Exponencial combinada com a tecnologia. Uma alternativa de continuidade do estudo seria propor situações-problema de modo que os alunos passassem da situação particular trabalhada, no conjunto dos números naturais, para situações que envolvam os números reais e, assim, trabalhar com diferentes softwares de construção gráfica, como GraphEq, Winplot, Graphmat, Geogebra, entre outros, no intuito de verificar o comportamento das funções e o estabelecimento das relações entre as variáveis. 


\section{Referências Bibliográficas}

BARROSO, D. F. Construindo o conceito de função exponencial através dos objetos digitais de aprendizagem Torre de Hanói e GeoGebra. In D. F. Barroso (Ed.), V Encontro Mineiro de Educação Matemática (pp. 1-46). Lavras: UFL, 2009.

BERLEZE, C. S. Uma Sequência de Ensino Usando o Programa Winplot: em busca de uma aprendizagem autônoma do aluno. Dissertação de Mestrado em Ensino de Física e de Matemática, Centro Universitário Franciscano, Santa Maria, Brasil, 2007.

BICUDO, M. A. V.; GARNICA, A. V. M. Filosofia da Educação Matemática. Belo Horizonte: Autêntica, 2006.

BOGDAN. R. C.; BIKLEN, S. K. Investigação qualitativa em educação: uma introdução à teoria e aos métodos. Porto: Porto Editora, 1994.

D’AMBRÓSIO, U. Comportamento e conhecimento. Brasília: Universidade de Brasília, 1994.

DANTE, L. R. Didática na resolução de problemas de matemática. São Paulo: Ática, 2002.

DUVAL, R. Registros de representação semiótica e funcionamento cognitivo da compreensão da matemática. In: MACHADO, S. D. A. (Org.). Aprendizagem em Matemática: registros de representação semiótica. Campinas: Papirus, p. 11-33, 2003.

FREIRE, P. Pedagogia da Autonomia. São Paulo: Editora Paz e Terra, 1996.

GARCÍA, E. A natureza do conhecimento escolar: transição do cotidiano para o científico ou do simples para o complexo? In: Rodrigo, M. J.; Arnay, J. Conhecimento Cotidiano, Escolar e Científico: Representação e Mudança (75-102). São Paulo: Editora Ática, 1998.

GOMEZ-GRANELL, C. Rumo a uma epistemologia do conhecimento escolar: o caso da educação matemática. En: M. J. Rodrigo, J. Arnay (Eds.), Domínios do Conhecimento, Prática Educativa e Formação de Professores (15-42), São Paulo: Ática, 1998.

MARTINS, J. C. Vygotski e o papel das interações sociais na sala de aula: reconhecer e desvendar o mundo. Idéias, 28(1), 111-122, 1999.

MORAES, R., GALliAZZI, M. C. Análise Textual Discursiva. Ijui: Editora Unijui, 2007.

MOREIRA, M. A. A teoria da aprendizagem significativa e sua implementação em sala de aula. Brasília: Universidade de Brasília, 2006.

PONTE, J. P. O estudo de caso na investigação em educação matemática. Quadrante 3(1), 3-18, 1994. 
PORTANOVA, R. et. al. Um currículo de matemática em movimento. Porto Alegre: EDIPUCRS, 2005.

SILVA, R. S. O uso de problemas no ensino e aprendizagem de funções exponenciais e logarítmicas na escola básica. Dissertação de Mestrado em Ensino de Matemática, Instituto de Matemática da Universidade Federal do Rio Grande do Sul, Porto Alegre, Brasil, 2012.

SZTAJN, P. Resolução de Problemas, Formação de Conceitos Matemáticos e Outras Janelas Que Se Abrem. Educação em revista, 20(25), 109-122, 1997.

VERGNAUD, G. A teoria dos campos conceptuais. In: J. Brun (Ed.), Didáctica das Matemáticas (155-191), Lisboa: Instituto Piaget, 1996.

VYGOTSKY, L. S. Pensamento e Linguagem. São Paulo. Martins Fontes, 1987.

YIN, R. Estudo de caso: planejamento e métodos. Porto Alegre: Bookman, 2001. 